NASA Technical Memorandum 104476

\title{
Thermal Performance of a Liquid Hydrogen Tank Multilayer Insulation System at Warm Boundary Temperatures of 630,530 and $152^{\circ} \mathrm{R}$
}

Robert J. Stochl and Richard H. Knoll Lewis Research Center

Cleveland, Ohio

Prepared for the

27th Joint Propulsion Conference cosponsored by the AIAA, SAE, ASME, and ASEE Sacramento, California, June 24-27, 1991 
THERMAL PERFORMANCE OF A LIQUID HYDROGEN TANK MULTILAYER INSULATION SYSTEM

AT WARM BOUNDARY TEMPERATURES OF 630, 530 AND $152{ }^{\circ} \mathrm{R}$

Robert J. Stochl and Richard H. Knoll

National Aeronautics and space Administration

Lewis Research Center

Cleveland, Ohio 44135

\section{Abstract}

This report presents the results of an investigation conducted to obtain experimental heat transfer data on a liquid hydrogen tank insulated with 34 layers of MLI for warm side boundary temperatures of 630,530 , and $150{ }^{\circ} \mathrm{R}$. The MLI system consisted of two blankets, each blanket made up of alternate layers of double silk net (16 layers) and double-aluminized Mylar radiation shields (15 layers) contained between two cover sheets of Dacron-scrim-reinforced Mylar. The insulation system was designed for and installed on a 87.6-in.-diameter liquid hydrogen tank. Nominal layer density of the insulation blankets is 45 layers/in. The insulation system contained penetrations for structural support, plumbing and electrical wiring that would be representative of a cryogenic spacecraft. The total steady state heat transfer rates into the test tank for shroud temperatures of 630,530 , and $152^{\circ} \mathrm{R}$ were $164.4,95.8$, and $15.9 \mathrm{BTU} / \mathrm{hr}$ respectively. The noninsulation heat leaks into the tank (12 fiberglass support struts, tank plumbing, and instrumentation lines) represent between 13 to 17 percent of the total heat input. The net heat transfer through the MLI is $0.94,0.53$, and $0.09 \mathrm{BTU} / \mathrm{hr}-\mathrm{ft}^{2}$ for the 630,530 , and $152{ }^{\circ} \mathrm{R}$ shroud temperatures. These heat input values would translate to liquid hydrogen losses of $2.3,1.3$, and 0.2 percent/day, with the tank held at atmospheric pressure.

\section{Introduction}

The storage of cryogenic propellants for future space exploration missions will require lightweight high performance thermal protection systems. The type of thermal protection system used will be mission dependent but in most cases will require some type of multilayer insulation (MLI) containing between 50 and 200 layers. A preliminary review of the current MLI database for MLI technology indicates that thermal performance data is not available for the external boundary temperatures these systems would encounter during the various proposed mission scenarios. Studies have shown (Ref. 1) that lunar surface temperatures can range between 180 and $630^{\circ} \mathrm{R}$. Most of the experimental performance data available for MLI systems (i.e., Refs. 2 to 4) is concentrated around warm boundary temperatures of $530^{\circ} \mathrm{R}$.

The purpose of this report is to present the results of an investigation conducted at the NASA Lewis Research Center to obtain experimental heat transfer data on a test tank insulated with MLI, in a vacuum environment, at warm boundary temperatures of 630,530 , and $150{ }^{\circ} \mathrm{R}$. The MLI system consists of two blankets, each blanket made up of alternate layers of double silk net (16 layers) and double-aluminized Mylar radiation shields (15 layers) contained between two cover sheets of Dacron-scrim-reinforced Mylar. The insulation system was designed for and installed on a 87.6-in.-diameter liquid hydrogen tank. The insulation system was modularized to facilitate removal and/or replacement of insulation elements. Nominal layer density of the insulation blankets is 45 layers/in. The test tank was supported by low conducting fiberglass supports. The insulation system contained penetrations for these supports in addition to penetrations for plumbing and electrical wiring. The complete system closely represented a flightweight thermal protection system that could be representative of a cryogenic spacecraft. 
This tank and insulation system were previously tested in 1974 (Ref. 5) under conditions simulating both a near Earth orbit environment (hot side boundary of $\left.530^{\circ} \mathrm{R}\right)$ and a deep-space environment with payload-to-sun orientation. The deepspace tests involved holding the simulated payload at $530^{\circ} \mathrm{R}$ while the remaining environment was held at $40^{\circ} \mathrm{R}$. These tests demonstrated that liquid hydrogen could be stored, nonvented, for periods exceeding 120 days during interplanetary transfer with sun orientation. The $530{ }^{\circ} \mathrm{R}$ warm boundary test reported herein is a repeat of the near earth tests reported in Ref. 5 to determine any insulation degradation over 17 years.

\section{Experimental Apparatus}

$\underline{\text { Facility }}$

All tests were conducted inside a 25-ft.-diameter spherical vacuum chamber in order to minimize heat transfer by gaseous conduction and convection. The vacuum capability of this chamber was approximately $8 \times 10^{-7}$ torr.

A general schematic of the facility, test tank and associated equipment is shown in Fig. 1. The insulated test tank was placed inside a cylindrical shroud $13 \mathrm{ft}$ in diameter and $13 \mathrm{ft}$ long as shown in Fig. 2. The shroud was capable of either being cooled by flowing liquid nitrogen through the 1-in. diameter tubes welded to the outside surface, or heated by resistance heaters that were bonded to the surface between the tubes. All plumbing and instrumentation lines that enter or are attached to the test tank pass through a liquid hydrogen cold guard mounted off the shroud (Fig. 2). This minimized the solid conduction heat input into the test tank from these sources.

The pressures inside the test tank and cold guard were controlled by separate closed-loop systems capable of maintaining each pressure within \pm 0.02 psia. The pressures inside the test tank and cold guard were maintained at 17.00 and 17.50 psia respectively. The cold guard was maintained at a higher pressure (with its resulting higher saturation temperature) to prevent the vaporized gas flow from the test tank being condensed as it passed through the cold guard.

The total heat transfer into the test tank was determined from one of four volume flow-meters measuring the gas boil-off flow rate. The steady-state heat transfer rate was directly proportional to the gas flow rate since the pressure was held constant (within $\pm 0.02 \mathrm{psia})$. The flow capacity of the four flow-meters were 10, 100, 300, and 1500 standard cubic feet of gaseous hydrogen per hour.

\section{Test Configuration}

The test tank, multilayer insulation system and instrumentation used for this test program, described in detail in Ref. 5, is summarized here.

Test tank. The liquid hydrogen test tank shown in Fig. 3 was fabricated by joining two halves of a $1.2 / 1.0$ oblate spheroid by a 1.5-in. cylindrical section. The major and minor diameters of the oblate spheroid are 87.6 and 73.0 in. respectively. The internal tank volume is $175 \mathrm{ft}^{3}$. The tank is constructed of 2219-t62 aluminum with a design working pressure of 80 psid. Both the upper and lower shells of the tank were chemically milled to a membrane thickness of between 0.077 and $0.087 \mathrm{in}$. The weld lands were $0.180 \mathrm{in}$. thick. The tank was supported by 12 fiberglass struts attached to brackets welded to lands on the lower half of the tank.

Insulation system. The basic insulation system shown in Fig. 4 consisted of two blankets. Each blanket contained 15 double-aluminized Mylar radiation shields alternately spaced between 16 double layers of silk net spacers with two outer structural cover sheets of reinforced double-aluminized Mylar (Schjeldahl $\mathrm{X}-850$ ). The original design data for these materials are listed in Table 1. The blankets were held together with 
nylon button-pins and retainers (Fig. 5) located on 8-in. centers. These buttonpins and retainers were cemented to the cover sheets to provide a positive means of layer density control for the insulation. The nominal insulation density, based on the button-pin-to-retainer dimension was 45 layers/in.

Each blanket consisted of $\operatorname{six}, 60^{\circ}$, gore panel sections with $3^{\circ}$ extensions on the inner and outer cover sheets on opposing edges to prevent direct radiation penetration at the seams. A continuous velcro-hook tape was cemented to the surfaces of the cover sheet extensions that faced the tank. Mating intermittent velcro-pile tape was cemented to the outward-facing surfaces of the cover sheets and to the tank itself. The details of the gore panel insulation are shown in Fig. 6. The outer blanket gore panel was off-set from the inner blanket by $6^{\circ}$. This offset butt joint was designed primarily to minimize seam heat leak. The off-set was achieved by shifting the location of the grommets in each blanket by $6^{\circ}$. The grommets (six per panel) slipped over nylon positioning pins that were adhesively bonded to the tank surface. The insulated tank is shown in Fig. 7. The only difference between this tank and the one tested in Ref. 5 is the absence of a beta-cloth meteoroid shield and additional plumbing which had been added to support a no-vent fill technology test program.

Instrumentation. Instrumentation was provided for measuring the temperature of the insulation and shroud, temperature at various locations on the test hardware, pressures inside the test tank and cold guard, pressure in the vacuum chamber and the volume flow rate of the boil-off gas.

Thermocouples, platinum resistance temperature sensors (PRTS) and silicon diodes (SD) comprised the temperature transducers on the test configuration. All thermocouples on or within the insulation and on the fiberglass struts were 10-mil diameter Chromel-Constantan
$(\mathrm{Cr}-\mathrm{Cn})$. Each $\mathrm{Cr}-\mathrm{Cn}$ measurement channel had an uncertainty of $\pm 7.0^{\circ} \mathrm{R}$ at liquid hydrogen temperature. This uncertainty improved to $\pm 1.0^{\circ} \mathrm{R}$ at room temperature. The use of PRTS were confined to the tank wall, several locations on the fiberglass struts, mid-structure, and cryoshroud. The uncertainty of the PRTS ranged from \pm 0.4 to $\pm 3.0^{\circ} \mathrm{R}$ depending of their span range. Silicon diodes were used for measuring the temperature distribution in the additional fill lines and penetrations that were added to the tank, gas and liquid temperatures inside the tank, tank wall temperatures and temperatures at four locations radially through the insulation. The uncertainty of the SD's was estimated to be $\pm 0.5{ }^{\circ} \mathrm{R}$ at liquid hydrogen temperature and $\pm 2.0^{\circ} \mathrm{R}$ at room temperature.

Test tank, cold-guard, and line pressures were measured with bonded strain-gage transducers which had an uncertainty of \pm 0.25 percent of full scale.

The evaporation rate from the test tank was metered by one of a series of four volume flowmeters. These meters had full scale ranges of $10,100,300$, and 1500 standard cubic feet of gaseous hydrogen per hour with an uncertainty of \pm 0.5 percent of full scale.

All measurements were recorded by the NASA Lewis ESCORT-D (see Ref. 6 for details) mini-computer based system. The data was recorded once every $30 \mathrm{~min}$. during the tests.

\section{$\underline{\text { Procedure }}$}

In a typical experimental run, the vacuum chamber was evacuated to approximately $1 \times 10^{-5}$ torr and held at that level for at least $8 \mathrm{hr}$ in order to evacuate the interstitial gases from the multilayer insulation. The tank and the cold guard were then filled with liquid hydrogen against a controlled back pressure. The test tank was filled to approximately the 95 percent full level. The cold 
guard was filled until its vent line temperature indicated $37^{\circ} \mathrm{R}$. After the tank and cold guard temperatures stabilized, the tank and cold guard were vented to their normal operating pressures. This procedure served to ensure that the tanks contained saturated liquid. The tank and cold guard pressures were then controlled to $17.00 \pm 0.02$ and $17.50 \pm 0.02$ psia, respectively. The cold guard was controlled at a slightly higher pressure to prevent the boil-off flow from condensing in the vent line as it passed through the cold guard. The shroud temperature was then established by either cooling with liquid nitrogen or heating via heater strips mounted between the coolant tubes. The shroud temperatures were maintained to within $\pm 2.0^{\circ} \mathrm{R}$ of the desired set point by a closed-loop temperature control system.

Insulation temperatures and boil-off flow were monitored until steady-state thermal conditions were established. Steady state was defined to occur when temperatures through the insulation and boil-off flow rate did not vary by more than the error band of the measuring system based on a minimum of six consecutive readings spaced approximately $0.5 \mathrm{hr}$ apart.

\section{Data Analysis}

Steady-state heat transfer through the MLI system consists of a combination of radiation and conduction. The basic procedure used in this report is to subtract all known solid conduction heat flows from the heat equivalent of the boil-off values. The solid conduction contribution being the sum of: (1) Heat added by conduction down the 12 fiberglass struts, (2) By conduction through service lines and tubes connected to the test tank, and (3) By conduction through instrumentation and control wiring.

$$
\begin{aligned}
Q_{\text {insulation }}= & Q_{\text {boil }- \text { of } f} \\
& -Q_{\text {solid conduction }}-\Delta U
\end{aligned}
$$

where $Q_{\text {insulation }}$ is the total heat flow through the insulation system including heat conduction through the nylon positioning pins, any increased heat transfer through the blankets due to strut penetration and any heat transfer due to the presence of seams and, $\Delta U$ is the change in system energy (ullage, tank wall, liquid and insulation). For the tests results reported herein the change in system energy was below our level of detection and, hence, was considered to be zero for all steady-state conditions.

The $Q_{\text {boil-off }}$ was evaluated from the
relation,

$$
Q_{\text {boil -off }}=v_{\text {bo }} \rho_{\text {stp }} h_{\text {fg }}
$$

where

$V_{\text {bo }}$ volume flow rate (standard cubic feet of gaseous hydrogen per hour)

$P_{\text {stp }}$ hydrogen density at standard conditions $=0.00521 \mathrm{lb} / \mathrm{ft}^{3}$

$h_{\text {fg }}$ latent heat of evaporation BTU/lb (function of tank pressure)

Solid conduction heat inputs were evaluated using the Fourier heat transfer equation

$$
Q_{\text {solid conduction }}=A / 1 \int k(T) d T
$$

where

1 distance between temperature sensors on the conduction heat path

A cross-sectional area of conduction path

\section{Results and Discussion}

The steady state heat transfer rates into the test tank for the three shroud temperatures are tabulated in Table 2 . The data obtained in Ref. 2 is also 
included for comparison purposes. The total heat transfer rate (as determined from the boil-off volume flow measurements) into the tank ranges from $15.9 \mathrm{BTU} / \mathrm{hr}$ for the $152{ }^{\circ} \mathrm{R}$ shroud temperature to $164.6 \mathrm{BTU} / \mathrm{hr}$ for the $630^{\circ} \mathrm{R}$ shroud. The total heat transfer at $530{ }^{\circ} \mathrm{R}$ is about 25 percent greater for this test than was reported in Ref. 5 . However, a portion ( $5.6 \mathrm{BTU} / \mathrm{hr}$ ) of this increase is the result of additional heat conductive paths that were not present in Ref. 2. As mentioned earlier, this tank was also used for other technology testing which had additional instrumentation and plumbing requirements which could not be removed for these tests. Some of these plumbing penetrations can be seen at the top of the tank in Fig. 7. The heat transfer through these conductive paths are given in Table 2 , and as noted, a portion of the increased heat transfer for these tests can be attributed to the increased instrumentation and plumbing conductive heat leaks. The net heat transfer through the insulation appears to be about 13 percent higher than that measured previously of the $530^{\circ} \mathrm{R}$ warm boundary temperature. This amounts to a insulation degradation of less than 1 percent per year. The heat flux, in terms of BTU/hr-ft ${ }^{2}$, is plotted in Fig. 8 for the three shroud temperatures. The heat fluxes shown would translate to liquid hydrogen losses of $0.2,1.3$, and 2.3 percent/day, with the tank maintained at atmospheric pressure, and subjected to boundary temperatures of 152,530 , and $630{ }^{\circ} \mathrm{R}$ respectively.

The steady state temperature profiles through the insulation are shown in Fig. 9. The temperature data shown are the inner (shield No. 1) and outer (shield No. 17) sheets of the inner blanket and the inner (shield No. 18) and outer (shield No. 34) sheets of the outer blanket. Shield No. 1 is the Schjeldahl $\mathrm{X}-850$ cover sheet nearest the tank wall and shield No. 34 is the cover sheet facing the shroud surface. There are three basic modes of heat transfer through MLI systems: (1) radiation, (2) solid conduction, and (3) gaseous conduction. The shield temperatures for the 630 and $530{ }^{\circ} \mathrm{R}$ shroud boundary temperatures are very close to a radiation type profile indicating that the dominant mode of heat transfer is radiation. However, at the lower $152{ }^{\circ} \mathrm{R}$ shroud case, the temperature profile is linear indicating that conduction has become the dominant mode of heat transfer. The temperatures for the 530

${ }^{\circ} \mathrm{R}$ case are slightly higher than those reported in Ref. 5 for the same shroud boundary temperature.

The remaining Figs. 10 to 18, show the transient heat transfer and insulation temperature data from the start of the tests through to the point where steady state conditions were established. The total heat input rate into the test tank, as determined from the volume flowrate, for the $530^{\circ} \mathrm{R}$ shroud boundary temperature is shown as a function of time in Fig. 10. The test starts with the filling of the test tank and cold-guard with liquid hydrogen against a controlled back pressure. During this fill process, which lasted approximately $1 \mathrm{hr}$, the test tank is vented to atmosphere without measurement of the outflow rate. Once filled the tank and cold-guard pressures were slowly decreased to their respective operating pressures. A time history of the tank and cold-guard pressures are shown in Fig. 11. Notice that the coldguard had to be refilled approximately $21 \mathrm{hr}$ into the test. Once the test tank reached its operating pressure ( 17.0 psia) the boil-off flow was diverted through the volume flow meters. From this flow the heat input was determined. During the initial phase of this test several processes are occurring. The test tank wall and inner layers of insulation are being cooled by the filling of the tank with liquid hydrogen. As the insulation temperatures decrease the heat input into the tank decreases. The initial decrease in indicated heat flux is magnified by the fact that a large portion of the initial heat input goes into raising the bulk liquid temperature to the saturation temperature corresponding to the tank pressure. The heating of the bulk liquid to the saturation point 
is shown in Fig. 12. As the liquid approaches the saturation point a larger portion of the heat input goes into the evaporation of liquid, which results in an increase in the indicated heat input shown in Fig. 10. When the liquid is saturated all the heat input into the tank goes into evaporation of the liquid. At this point the total heat input is determined by the temperature profiles through the various conductive paths and through the insulation. The temperature history through the insulation is shown in Fig. 13. Steady state temperatures and therefore steady state heat input was reached in approximately $50 \mathrm{hr}$. Note the drop in the temperature of shield No. 1. This drop in temperature, occurring when the cold-guard was refilled, was also reported in Ref. 2 and was attributed to a temporary increase in local pressure from a hydrogen leak during the fill period.

Figures 14 to 16 show the total heat transfer, insulation temperature, and shroud temperature histories leading to steady state conditions for a steady state shroud boundary temperature of $630{ }^{\circ} \mathrm{R}$. Here again the data begins with the filling of the test tank and coldguard. The shroud was maintained at $530^{\circ} \mathrm{R}$ for about $11 \mathrm{hr}$ into the test (Fig. 16) before a facility problem could be corrected. Then the shroud temperature was raised to $630^{\circ} \mathrm{R}$. The total indicated heat input into the tank is shown to decrease in Fig. 14, once the volume flow starts to be recorded. There is then a rapid increase in the heat input when the shroud temperature was increased. The rate of increase then begins to level off as the bulk liquid reaches the saturation condition. The heat input then is dependent upon the increasing temperatures through the insulation as shown in Fig. 15. Again there is the drop in the temperature of the inner sheet (shield No. 1) when the coldguard is filled.

The total heat transfer and insulation temperature histories with the shroud boundary of $152{ }^{\circ} \mathrm{R}$ are shown in
Figs. 17 and 18 respectively. The same heat transfer trend is evident during the $530^{\circ} \mathrm{R}$ shroud test as the insulation temperatures decrease to their steady state value. The only deviation in trends for this test is that the temperature of the inner sheet does not decrease when the cold guard was filled (the cold guard was filled approximately $16 \mathrm{hr}$ into the test and again at the $54 \mathrm{hr}$ ). Conduction is the dominant mode of heat transfer at these low shield temperatures. As a result the increased gaseous conduction because of the increased pressure at the tank wall (from the leak) does not influence the shield temperature.

\section{Summary of Results}

This report presents the results of an investigation conducted to obtain experimental heat transfer data on an multilayer insulation for hot side boundary temperatures of 630,530 , and $150^{\circ} \mathrm{R}$. The multilayer insulation system consisted of two blankets, each blanket made up of alternate layers of double silk net (16 layers) and double-aluminized Mylar radiation shields (15 layers) contained between two cover sheets of Dacron-scrimreinforced Mylar. The insulation system was designed for and installed on a 87.6-in-diameter liquid hydrogen tank.

The total steady state heat transfer rates into the test tank for shroud temperatures of 630,530 , and $152{ }^{\circ} \mathrm{R}$ were $164.4,95.8$, and $15.9 \mathrm{BTU} / \mathrm{hr}$ respectively. The noninsulation heat leaks into the tank (12 fiberglass support struts, tank plumbing, and instrumentation lines) represent between 13 to 17 percent of the total heat input. The net heat transfer through the multilayer insulation is $0.94,0.53$, and $0.09 \mathrm{BTU} / \mathrm{hr}-\mathrm{ft} \mathrm{f}^{2}$ for the 630, 530, and $152{ }^{\circ} \mathrm{R}$ shroud temperatures. These heat input values would translate to liquid hydrogen losses of $2.3,1.3$, and 0.2 percent/day, with the tank held at atmospheric pressure.

The total heat transfer at $530^{\circ} \mathrm{R}$ is about 25 percent greater for this test 
than was reported in Ref. 5. There is a 13 percent degradation in the MLI performance, which averages out to less than

1 percent/year.

\section{References}

1. Tatom, Frank B., Ramakrishna, K.V., and Vaughan, O.H.: "Study of the Lunar Thermal Environment," Transactions of 1967 National Symposium on Saturn V/Apollo and Beyond, American Astronautical Society, June 12-14, 1967, Huntsville, AL.

2. Stochl, R.J.: "Basic Performance of a Multilayer Insulation System Containing 20 to 160 Layers," NASA TN D7659, Apr. 1974.

3. Keller, C.W.: "Thermal Performance of Multilayer Insulations," NASA CR-72747, Apr. 1971.
4. Walburn, A.B.: "Design and Development of Pressure and Repressurization Purge System for Reusable space Shuttle Multilayer Insulation Systems," GDC CASD-NAS-74-032, Aug. 1974 .

5. Knoll, R.H. and DeWitt, R.L.: "Thermal Performance of a Modularized Replaceable Multilayer Insulation System for a Cryogenic stage. NASA TN D-8282, 1977.

6. Fronek, D.L., et al.: "A Distributed Data Acquisition System for Aeronautics Test Facilities," NASA TM-88961.

TABLE 1. - DESIGN DATA FOR MLI BLANKET MATERIALS

\begin{tabular}{|c|c|c|c|c|}
\hline \multirow[t]{2}{*}{ Item } & \multirow[t]{2}{*}{ Material } & \multirow{2}{*}{$\begin{array}{l}\text { Room-temperature } \\
\text { emissivity }\end{array}$} & \multicolumn{2}{|c|}{ Unit weight } \\
\hline & & & $\mathrm{g} / \mathrm{cm}^{2}$ & $\mathrm{lb} / \mathrm{ft} \mathrm{t}^{2}$ \\
\hline $\begin{array}{l}\text { Radiation } \\
\text { shield }\end{array}$ & $\begin{array}{l}0.0064-m \text { (1/4-mil) } \\
\text { double-aluminized Mylar }\end{array}$ & $<0.04$ on both sides & 0.000884 & 0.00181 \\
\hline Shield spacer & $\begin{array}{l}4.7 \times 7.1 \text { mesh per } \mathrm{cm}^{2} \\
\left(12 \times 18 \text { mesh/in. }{ }^{2}\right) \text { silk net of } \\
\text { thickness } \leq 0.010 \mathrm{~cm}(\leq 0.004 \text { in. })\end{array}$ & 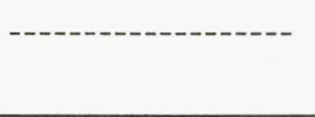 & $\leq 0.000732^{a}$ & $\leq 0.0015^{a}$ \\
\hline $\begin{array}{l}\text { Blanket cover } \\
\text { sheet }\end{array}$ & $\begin{array}{l}\text { Schjeldahl } x-850 \text {, which is a } \\
\text { laminate of } \\
\text { (a) } 0.0064-m \text { (1/4-mil) } \\
\text { single-aluminized Mylar } \\
\text { (b) Dacron scrim } \\
\text { (c) } 0.013-m \text { (1/2-mil) } \\
\text { single-aluminized Mylar }\end{array}$ & $\begin{array}{l}\leq 0.05 \text { on both sides } \\
\leq 0.05 \text { on aluminized } \\
\text { surface } \\
\leq 0.05 \text { on aluminized } \\
\text { surface }\end{array}$ & $\begin{array}{l}0.0078 \\
.000884 \\
.0020 \\
.00177\end{array}$ & $\begin{array}{l}0.016 \\
.00181 \\
.00419 \\
.00362\end{array}$ \\
\hline
\end{tabular}

$a_{\text {Per single layer. }}$ 
TABLE 2. - SUMMARY OF HEAT TRANSFER RESULTS

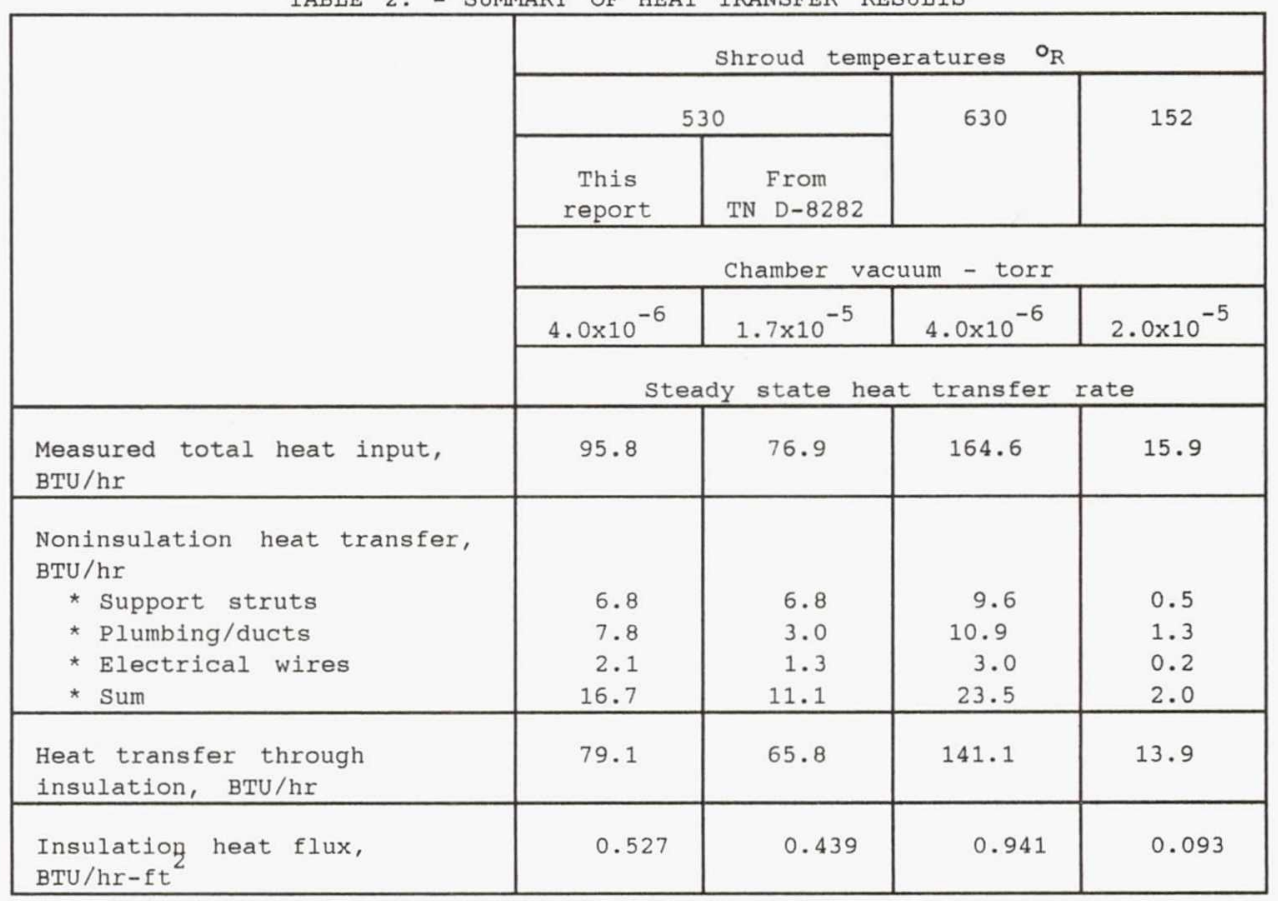




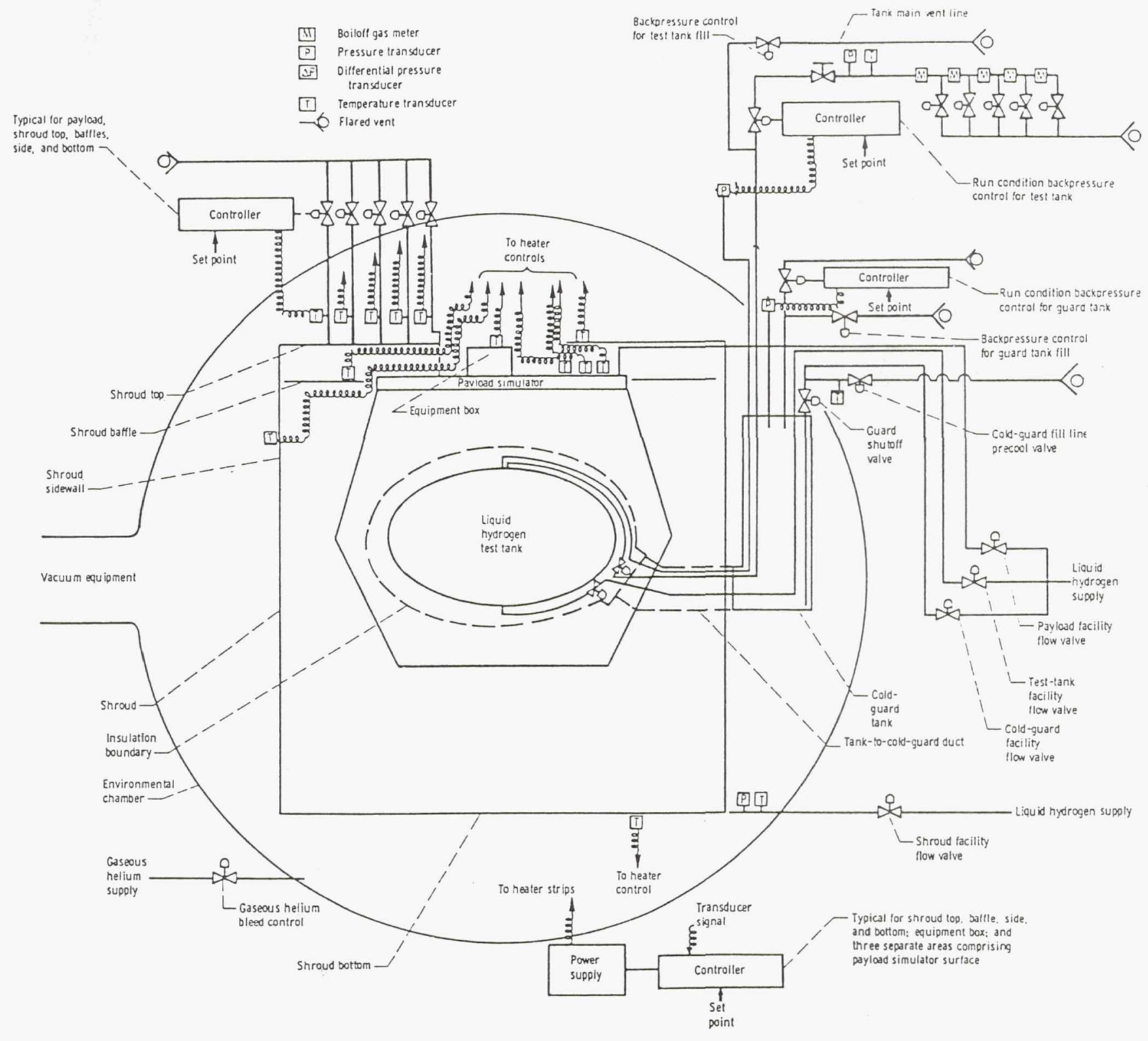

Figure 1. - General schematic of the facility 


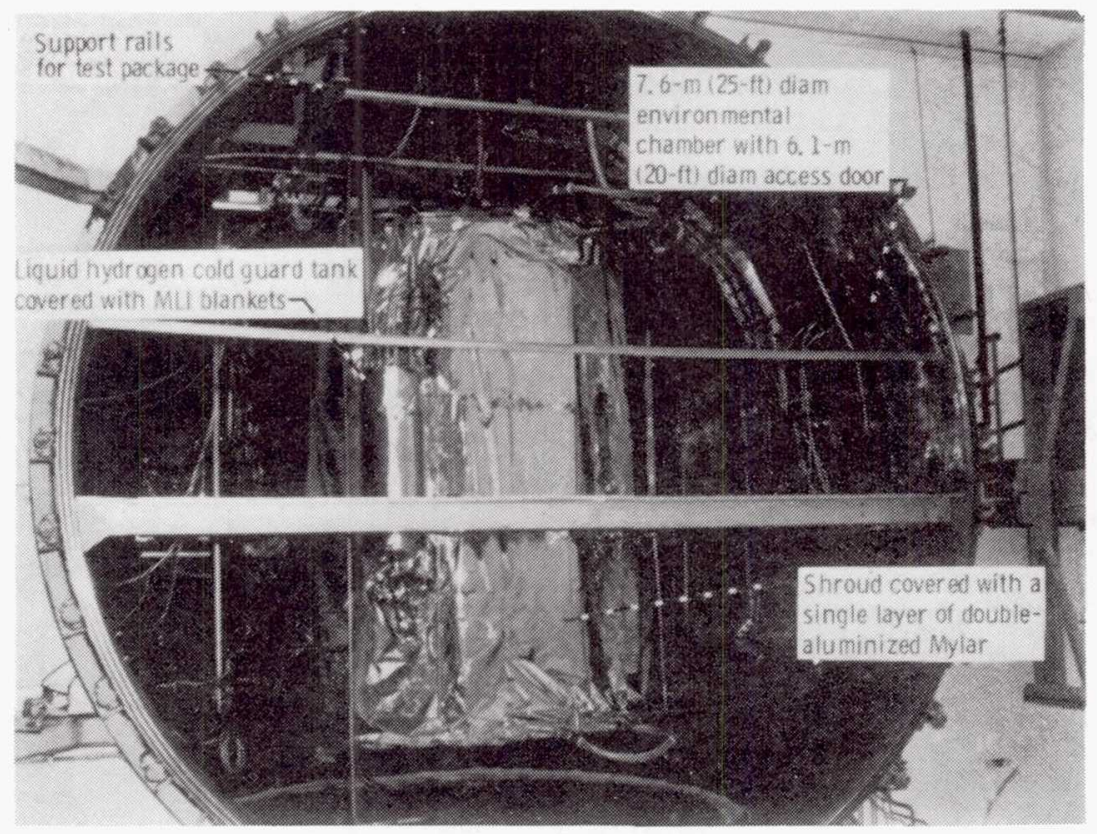

Figure 2. - Shroud mounted inside chamber

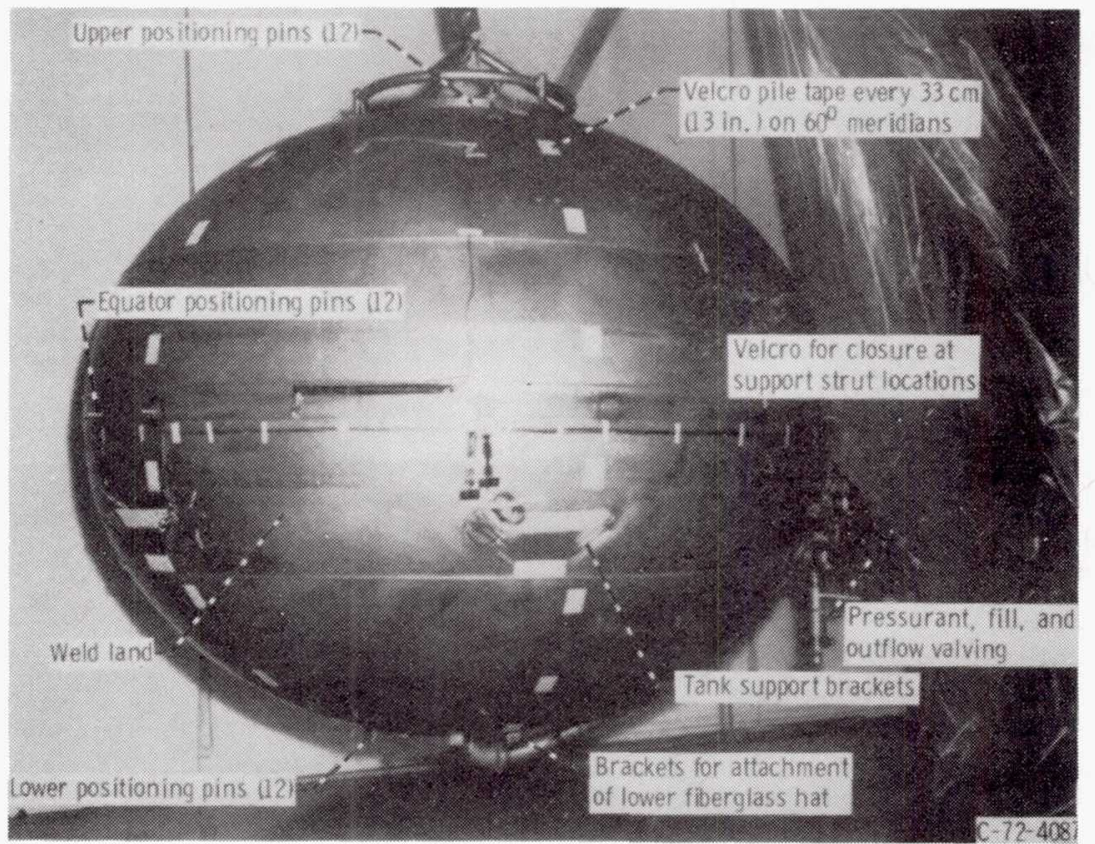

Figure 3. - Liquid hydrogen test tank 


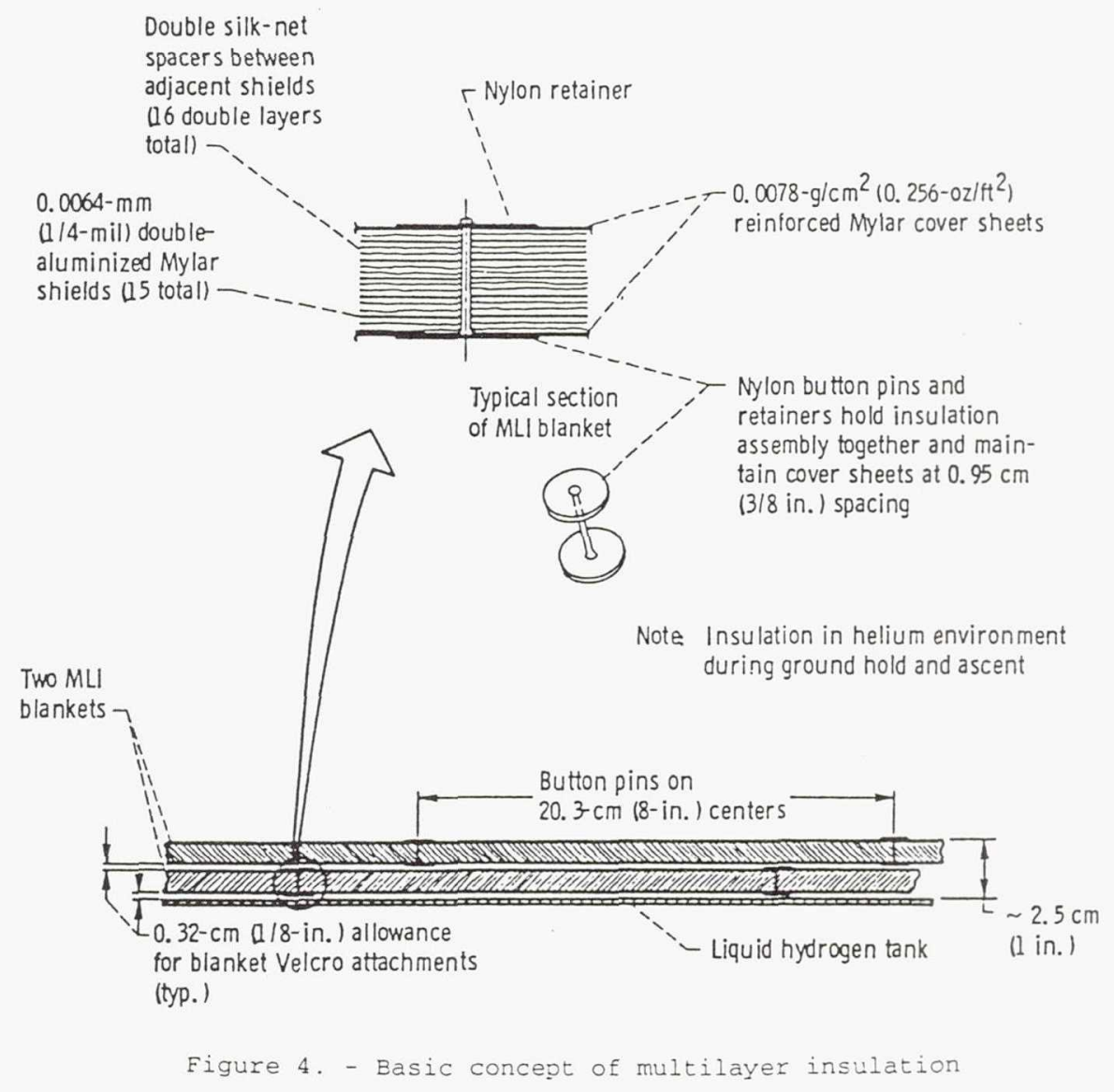



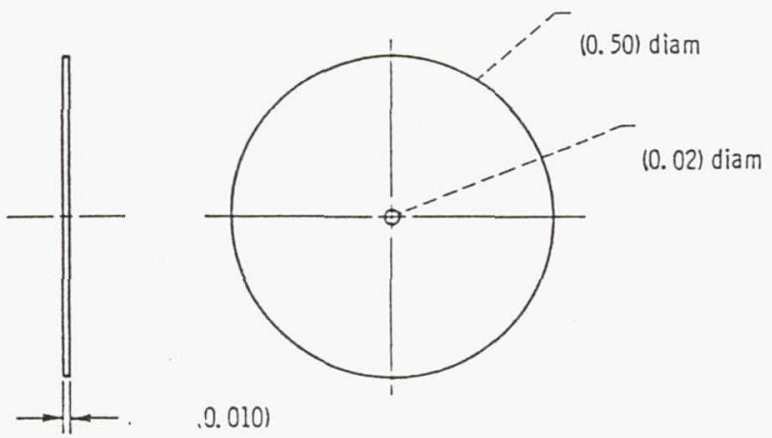

(a) Retainer.

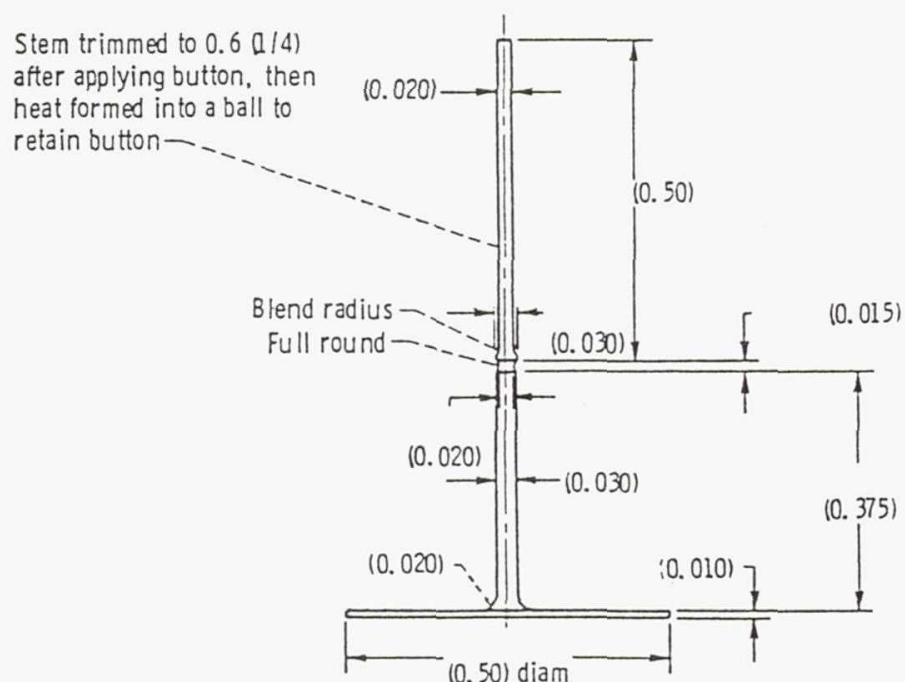

b) Button pin.

Figure 5. - Details of button pin retainer 


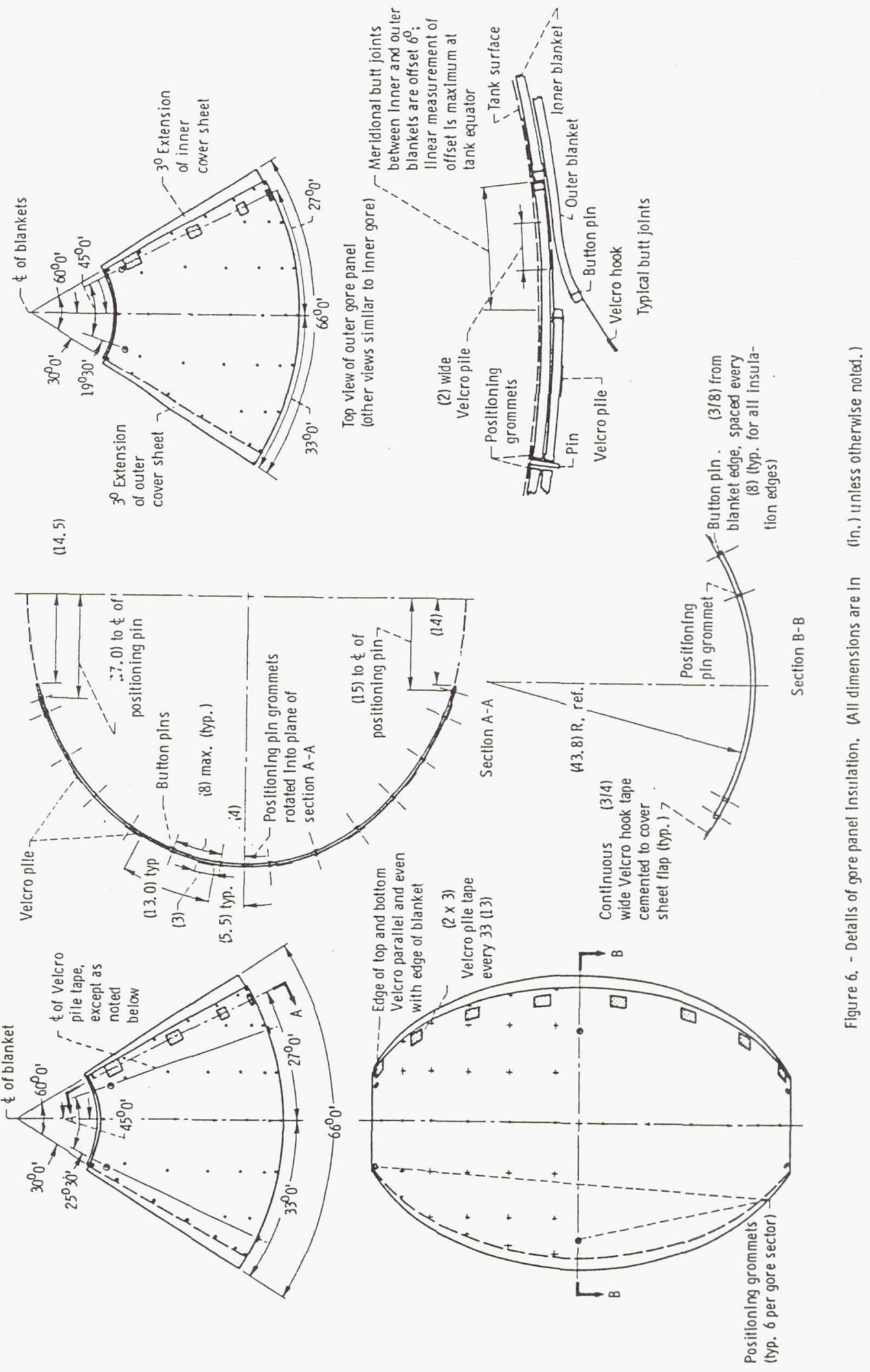




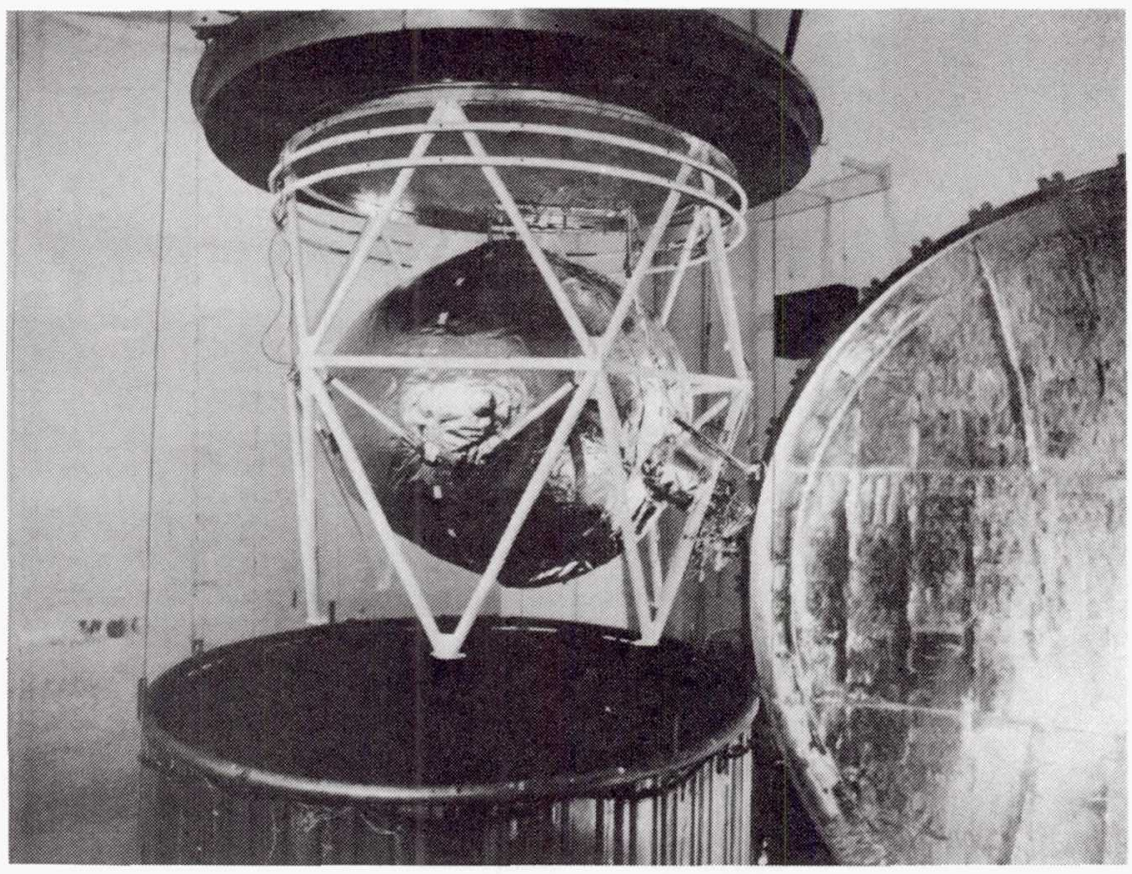

Figure 7. - Insulated test tank

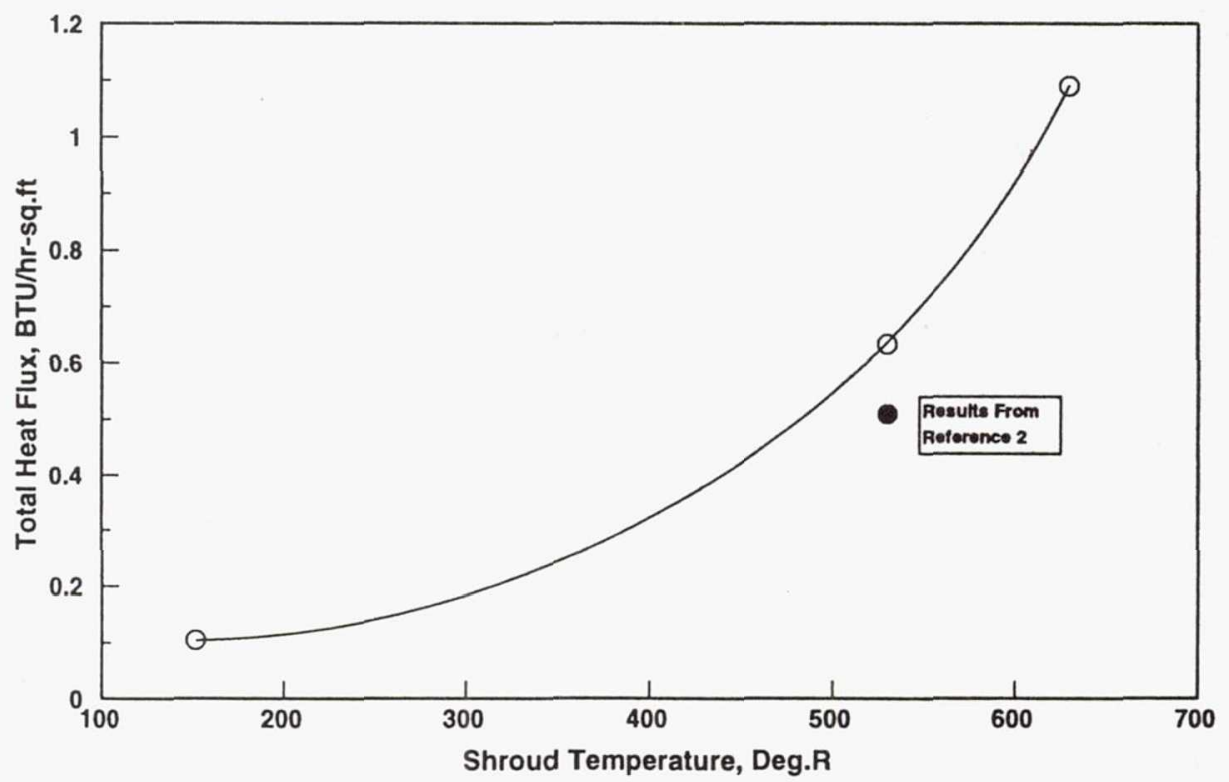

Figure 8. - Heat flux through $\mathbf{3 4}$ layers of MLI for three shroud temperatures 


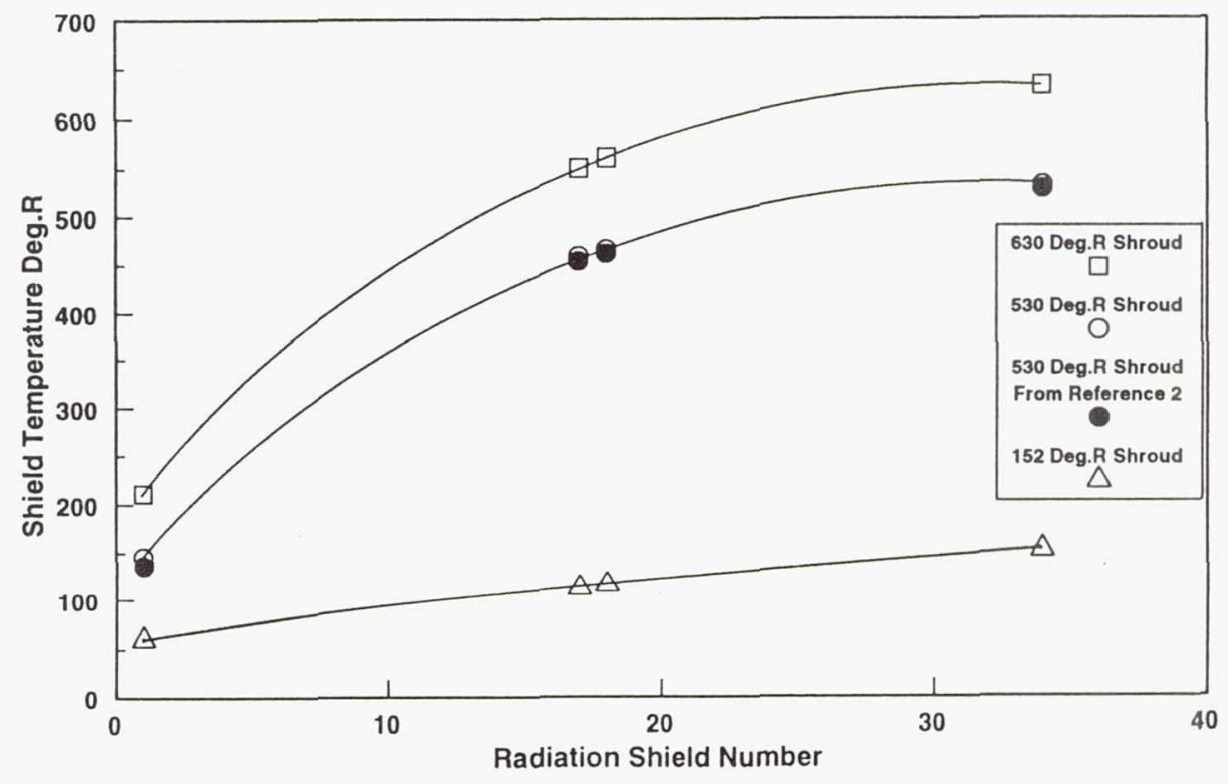

Figure 9. - Temperature profile through 34 layers of MLI for three shroud temperatures

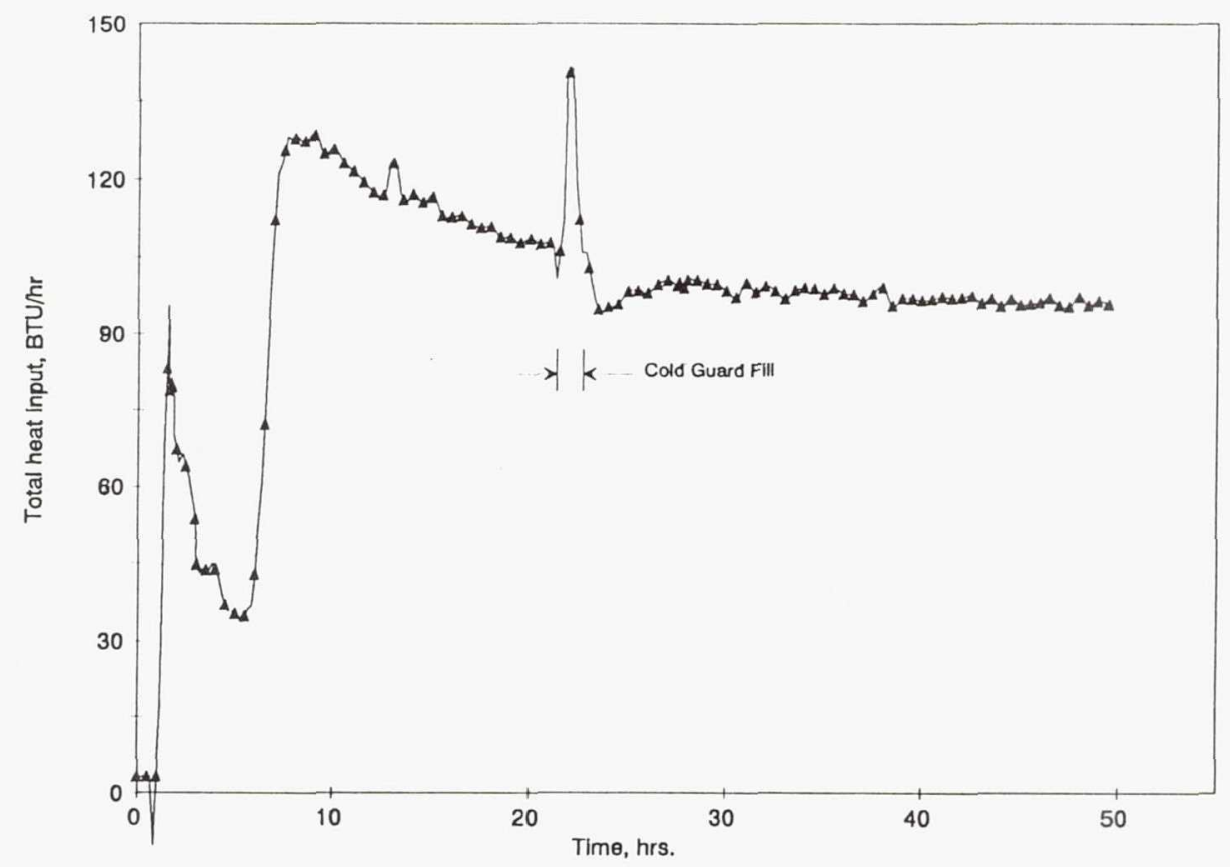

Figure 10 - Measured heat input into the tank over the test duration with the shroud at 530 degrees $R$. 


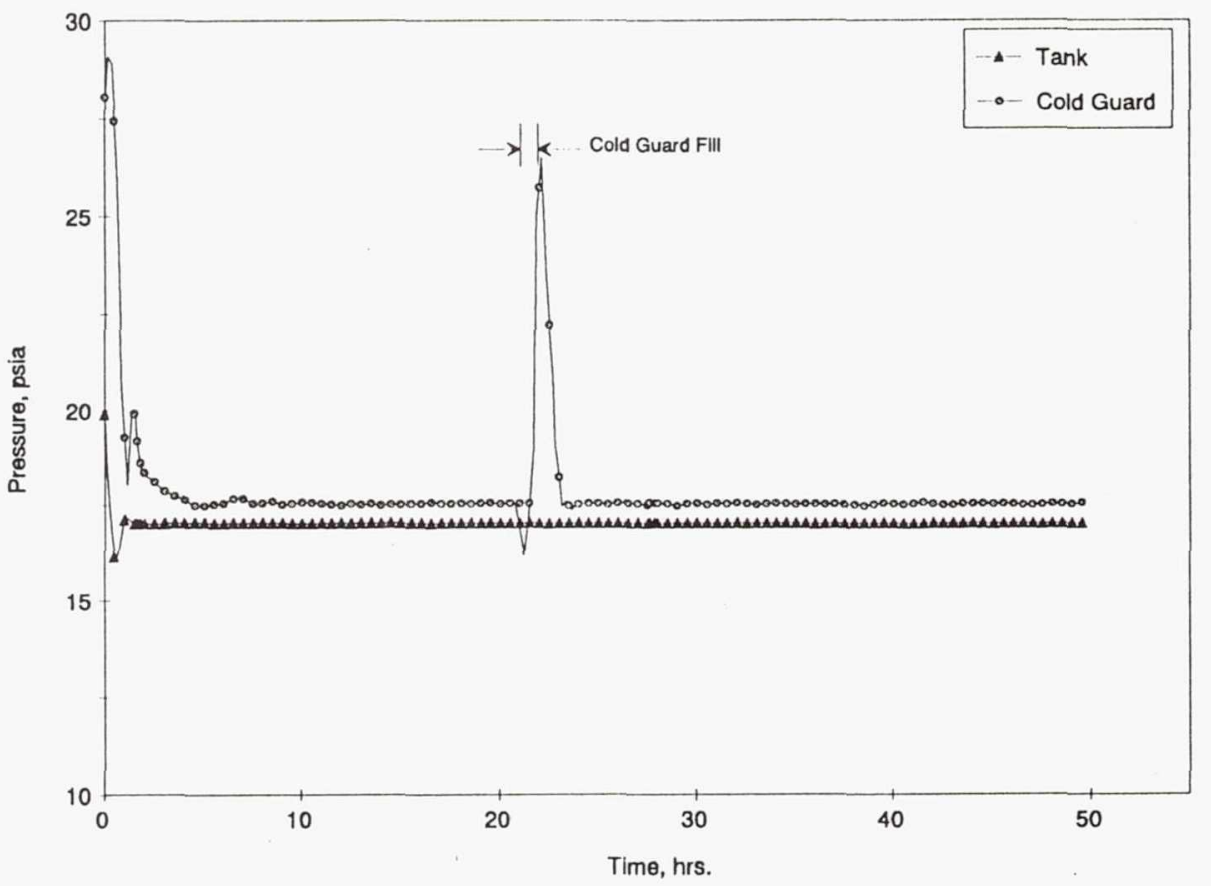

Figure 11. - Tank and cold guard pressures during the test with the shroud at 530 degrees $R$.

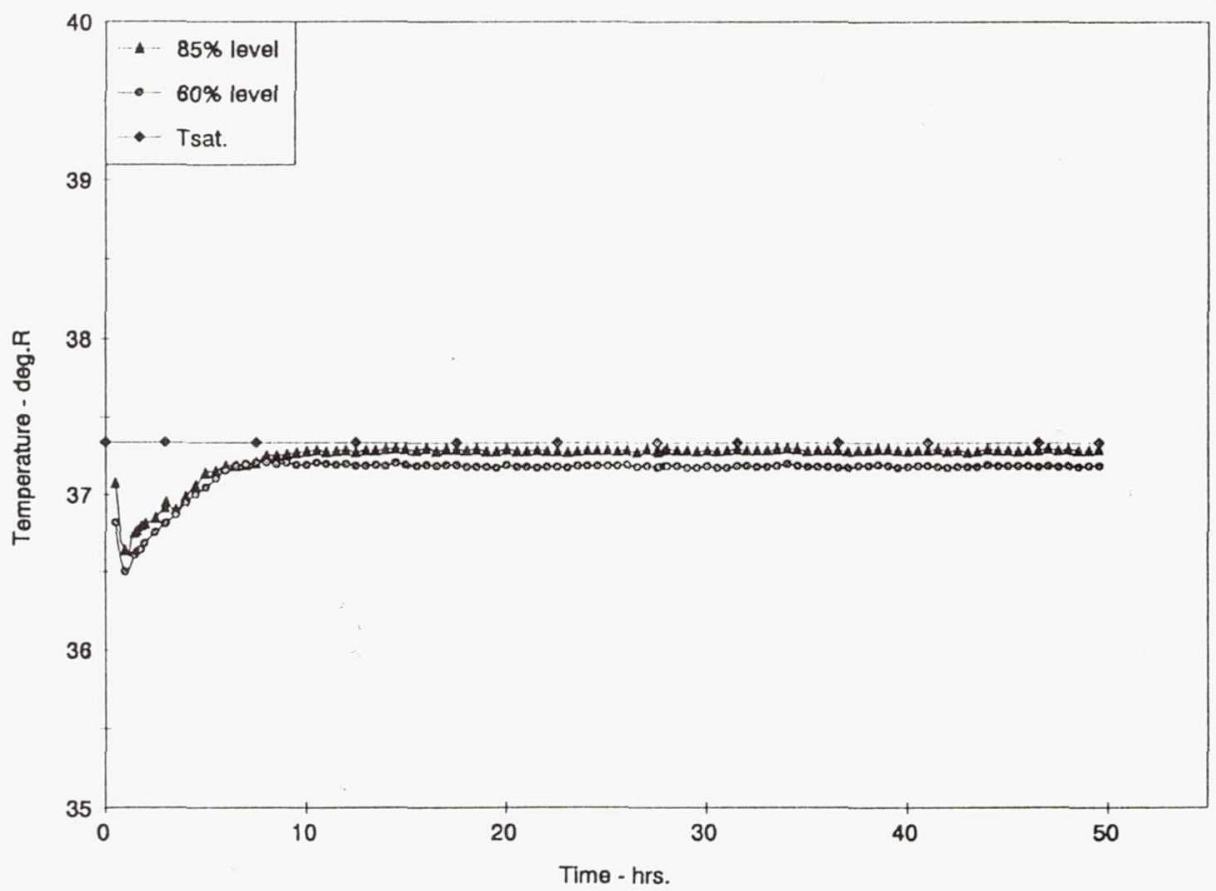

Figure 12. - Reprensetive liquid temperatures as a function of time during the 530 degree $\mathrm{R}$ shroud test 


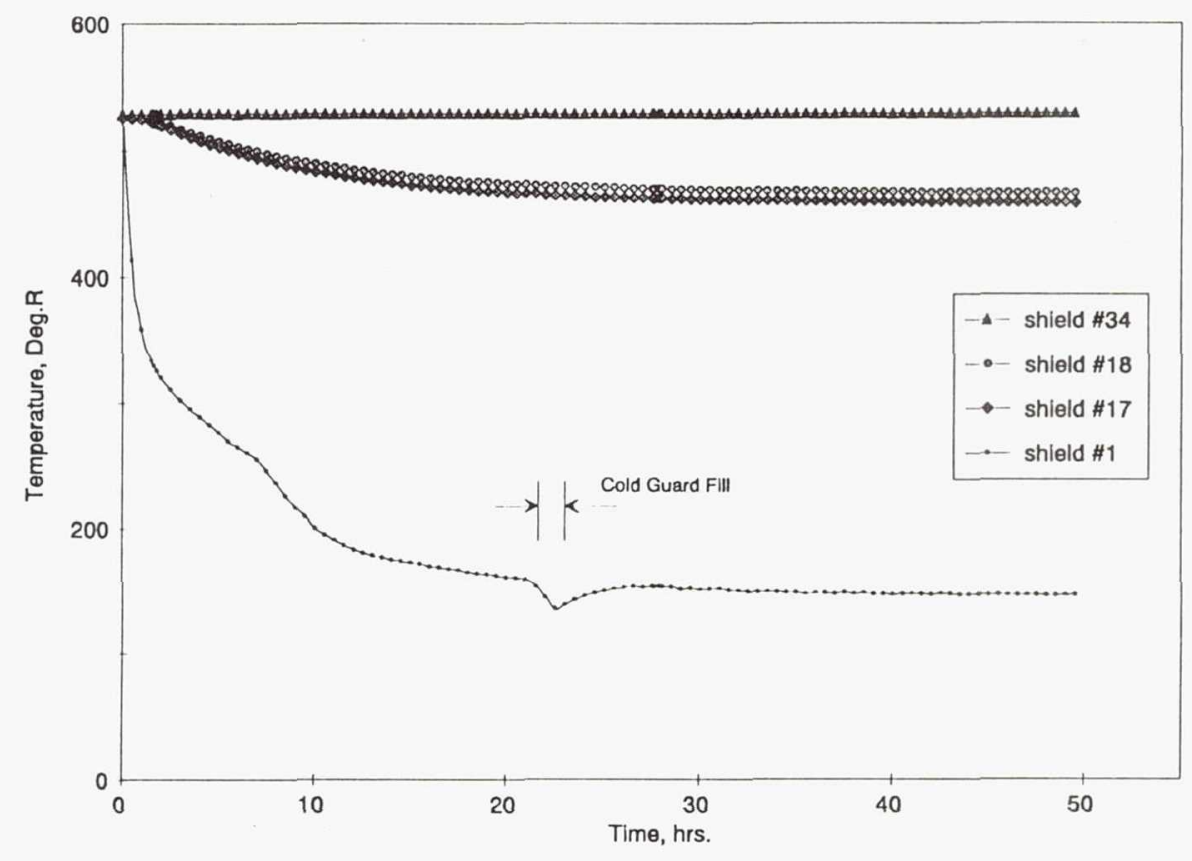

Figure 13. - Insulation temperature history during the test with the 530 degree $R$ shroud

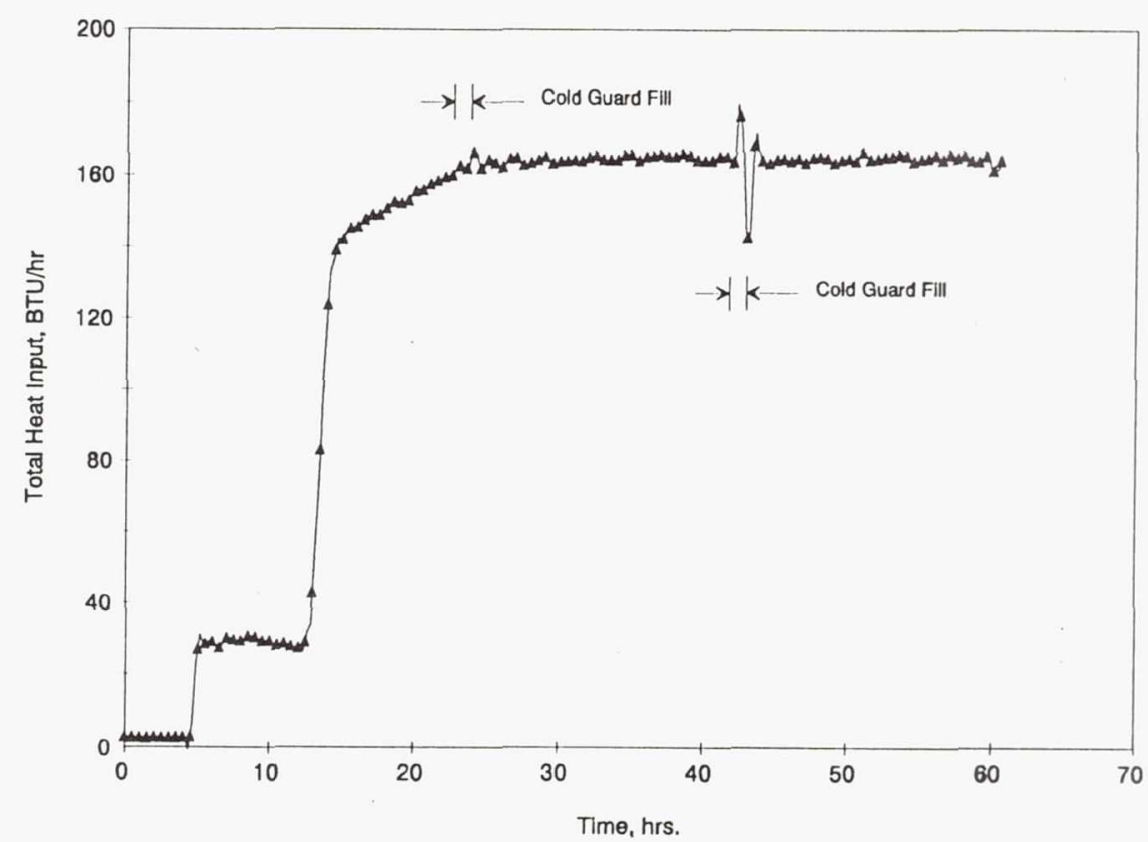

Flgure 14. - Measured heat input into the tank over the test duration with the shroud at 630 degrees $\mathrm{R}$. 


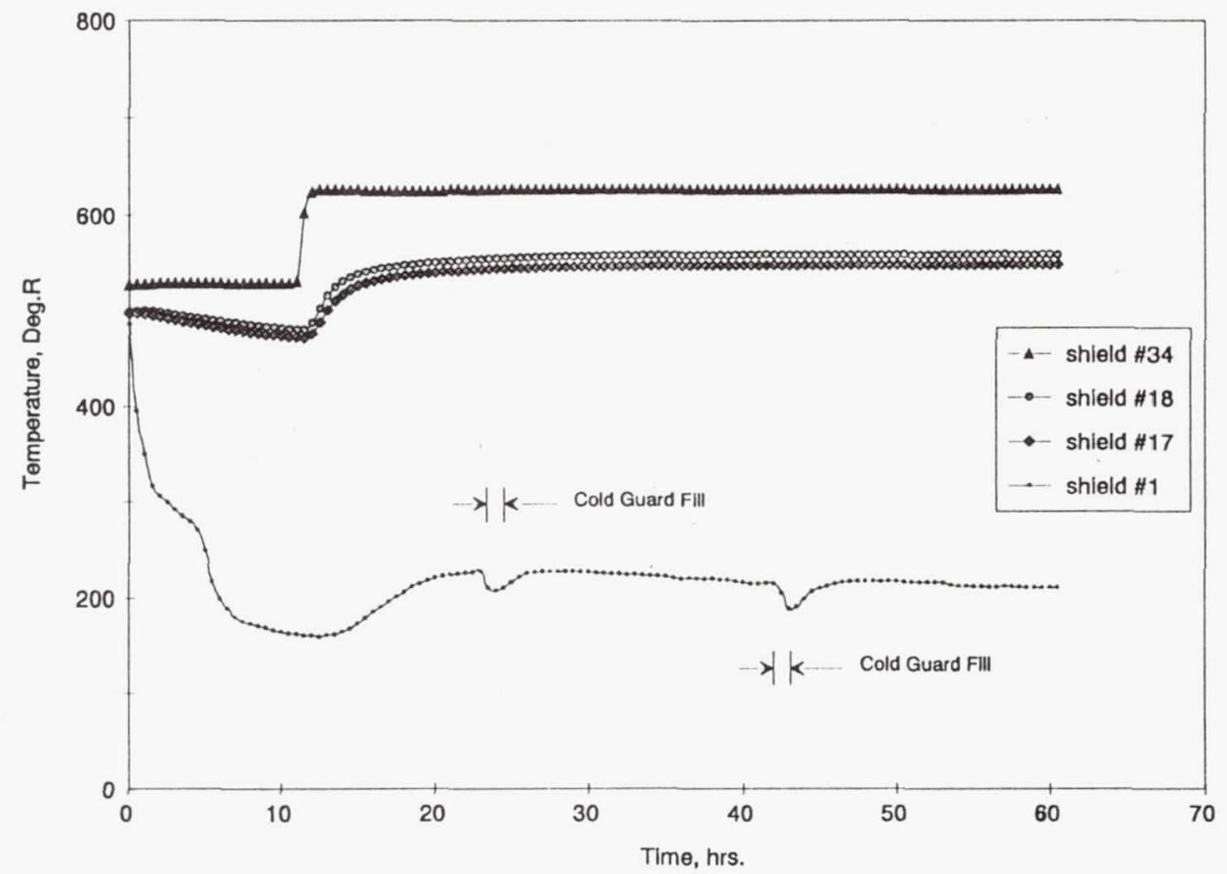

Figure 15. - Insulation temperature history during the test with the 630 degree R. shroud

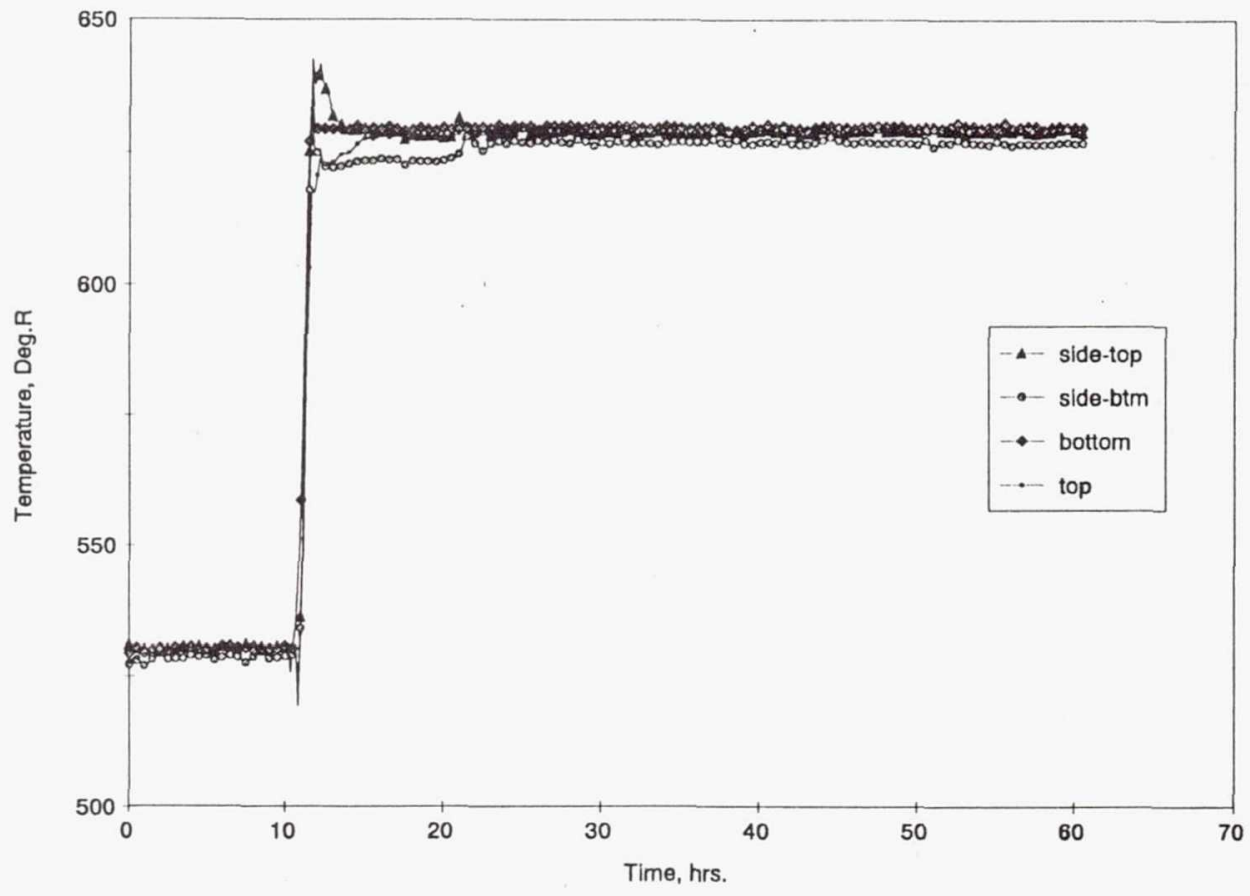

Figure 16. - Shroud temperature history simulating the 630 degree R. environment 


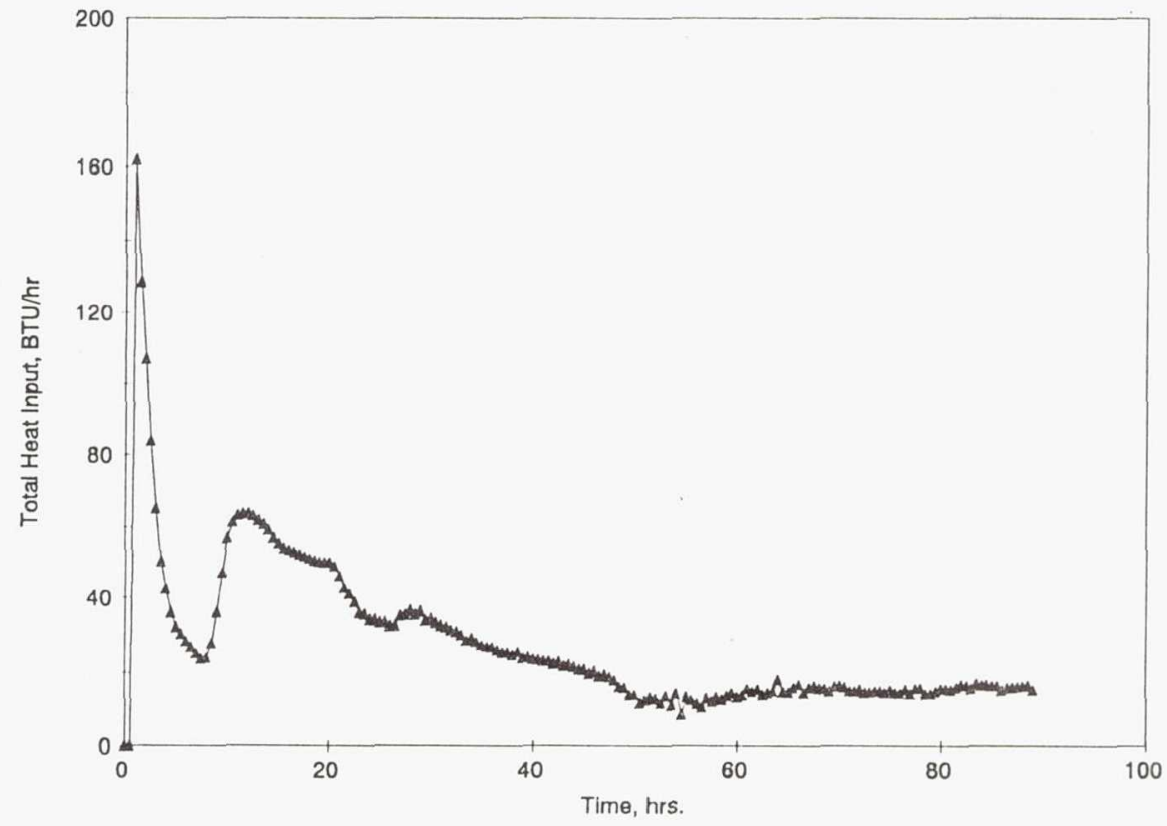

Figure 17. - Measured heat input into the tank over the test duration with the shroud at 152 degrees $\mathrm{R}$

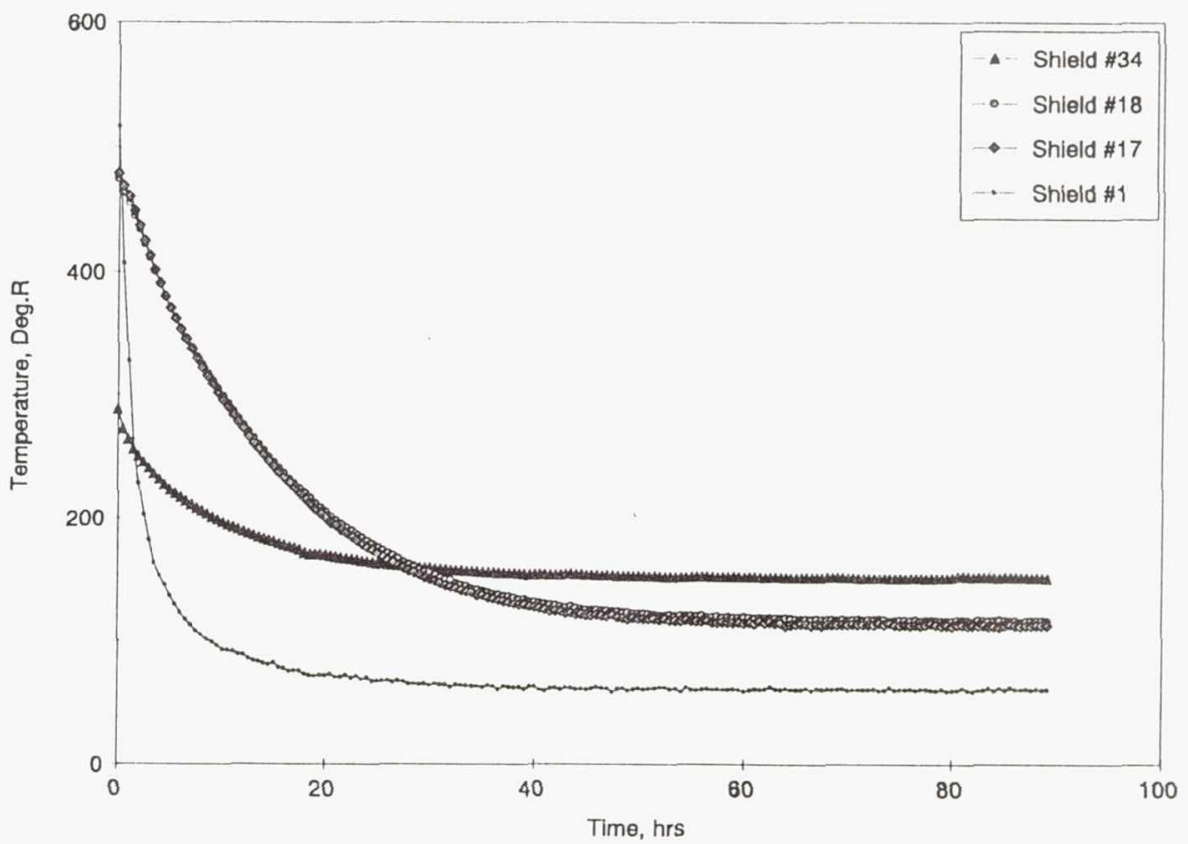

Figure 18. - Insulation temperature history during the test with the 152 degree shroud 


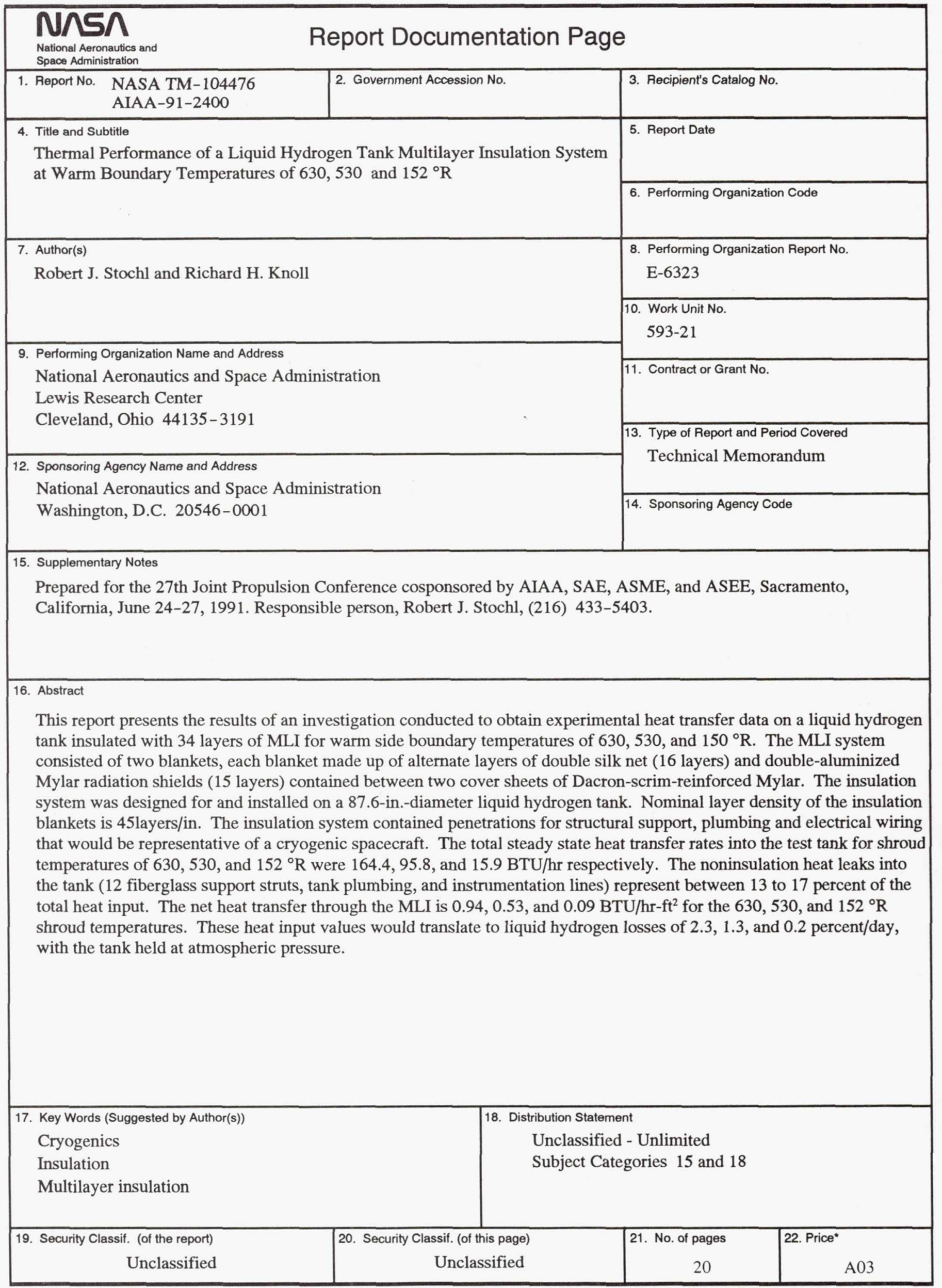

